\title{
EDITORIAL
}

\section{The Berlin definition: real change or the emperor's new clothes?}

\author{
Charles R Phillips*
}

The Berlin consensus group met recently after 18 years of defining acute respiratory distress syndrome (ARDS) using the American European Consensus Committee (AECC) criteria because, in their words, 'a number of issues regarding various criteria of the AECC definition have emerged, including a lack of explicit criteria for defining acute, sensitivity of $\mathrm{PaO}_{2} / \mathrm{FiO}_{2}$ to different ventilator settings, poor reliability of the chest radiograph (CXR) criterion, and difficulties distinguishing hydrostatic edema' [1]. Save for defining acute, they arrived at a new definition using nearly these exact same criteria and thus did not answer their original concerns.

When defining ARDS, as the late Daniel Schuster championed for years, the definition should include some direct measure of lung injury, at once eliminating much of what confounds the AECC and now the Berlin criteria - atelectasis, aspiration, effusion, pneumonia, left ventricular dysfunction, and the effects of ventilator settings on the $\mathrm{PaO}_{2} / \mathrm{FiO}_{2}$ ratio and CXR. This idea has been dismissed for years on grounds of feasibility - and dismissed yet again in Berlin - but given the very poor predictive value of the Berlin criteria for outcome and poor correlation with postmortem findings as regards severity classification and proper identification [2], I would argue it is indeed time to take another look. If we are to progress in our research efforts, it becomes imperative to identify homogeneous treatment groups specific to a treatment strategy. Berlin criteria do not have the reliability, sensitivity or specificity to do so or even to properly prognosticate. An area under the receiver operating characteristic curve of 0.577 (95\% confidence interval, 0.561 to 0.593 ) regarding the predictive validity for mortality found for the Berlin definition is abysmal, and should not be pointed to as progress. Quite the contrary, it is a rallying call for change.

*Correspondence: phillipc@ohsu.edu

Department of Medicine, Oregon Health and Science University, 3181 SW Sam Jackson Park Road, UHN-67, Portland, OR 97239, USA
The idea that hydrostatic and permeability causes of edema and hypoxemia are mutually exclusive, as implied by the AECC and now by the Berlin group, should be abandoned. Cardiomyopathy of sepsis and acute heart failure are common in ARDS - occurring in upwards of $60 \%$ of patients with severe sepsis - the number one cause of ARDS [3]. Considering that left ventricular dysfunction and cardiomyopathy of severe systemic inflammatory response syndrome/sepsis have better prognoses than diffuse alveolar injury, some measure of the relative contribution to CXR and $\mathrm{PaO}_{2} / \mathrm{FiO}_{2}$ ratio changes of hydrostatic versus pulmonary injury causes in ARDS then becomes important for identification, severity classification, prognostication and treatment.

Increased extravascular lung water is at the center of the pathophysiologic changes in ARDS. Indexing extravascular lung water to pulmonary blood volume - the pulmonary vascular permeability index - allows for the determination of the relative contribution of hydrostatic versus permeability causes of edema [4,5]. More recently, Jozwiak and colleagues have found that the pulmonary vascular permeability index predicts outcome in ARDS, the lower the value the better - or, put another way, the greater contribution of hydrostatic causes of pulmonary edema relative to permeability and alveolar injury in ARDS, the better the prognosis [6]. Increased extravascular lung water and the pulmonary vascular permeability index were not included in the Berlin definition due to concerns of feasibility. But both measures require nothing more than a specialized arterial catheter plugged into a module available in most major bedside monitors worldwide. If we are to require positive pressure ventilation in our definition, why not consider lung water - is it not time to move forward? If not EVLW then perhaps deadspace fraction, or the distribution of injury and/or lung weight by Cat Scan, or a direct measure of permeability - some more direct measure of injury specific to ARDS.

Some may say that adding the requirement of positive pressure ventilation and a minimal continuous positive airway pressure/positive end-expiratory pressure $\geq 5 \mathrm{cmH}_{2} \mathrm{O}$ as done by the Berlin group is a move forward. But positive end-expiratory pressure $<5 \mathrm{cmH}_{2} \mathrm{O}$ is used 
in less than $1.3 \%$ of all patients with ARDS [7]. Furthermore, when controlling for the $\mathrm{PaO}_{2} / \mathrm{FiO}_{2}$ ratio, baseline positive end-expiratory pressure does not predict mortality. In contrast, after controlling for the baseline $\mathrm{PaO}_{2} /$ $\mathrm{FiO}_{2}$ ratio, baseline $\mathrm{FiO}_{2}$ does predict mortality [7]. Why therefore require continuous positive airway pressure/ positive end-expiratory pressure $\geq 5 \mathrm{cmH}_{2} \mathrm{O}$ while leaving highly confounded $\mathrm{CXR}$ and $\mathrm{PaO}_{2} / \mathrm{FiO}_{2}$ criteria essentially unchanged?

I am left wondering, then, whether the Berlin criteria represent real change and/or significant improvement. Reading the extensive published coverage and experiencing the fanfare and discussion at international symposia surrounding the release of the Berlin criteria, I am indeed reminded of the classic tale of the emperor's new clothes. Real change is still needed, before we all catch our death of cold.

\section{Abbreviations}

ARDS, acute respiratory distress syndrome; AECC, American European Consensus Committee; $\mathrm{CXR}$, chest radiograph; $\mathrm{PaO}_{2} / \mathrm{FiO}_{2}$, partial pressure of oxygen in arterial blood/fraction of inspired oxygen.

\section{Competing interests}

CRP is a member of Pulsion Medical Systems MAB.

Published: 1 August 2013

\section{References}

1. ARDS Definition Task Force; Ranieri VM, Rubenfeld GD, Thompson BT, Ferguson ND, Caldwell E, Fan E, Camporota L, Slutsky AS: Acute respiratory distress syndrome: the Berlin Definition. JAMA 2012, 307:2526-2533.
2. Thompson BT, Matthay MA: The Berlin definition of ARDS versus pathological evidence of diffuse alveolar damage. Am J Respir Crit Care Med 2013, 187:675-677.

3. Furian T, Aguiar C, Prado K, Ribeiro RV, Becker L, Martinelli N, Clausell N, Rohde LE, Biolo A: Ventricular dysfunction and dilation in severe sepsis and septic shock: relation to endothelial function and mortality. J Crit Care 2012, 27:319.e9-e15.

4. Monnet X, Anguel N, Osman D, Hamzaoui O, Richard C, Teboul JL: Assessing pulmonary permeability by transpulmonary thermodilution allows differentiation of hydrostatic pulmonary edema from ALI/ARDS. Intensive Care Med 2007, 33:448-453.

5. Kushimoto S, Taira Y, Kitazawa Y, Okuchi K, Sakamoto T, Ishikura H, Endo T, Yamanouchi S, Tagami T, Yamaguchi J, Yoshikawa K, Sugita M, Kase Y, Kanemura T, Takahashi H, Kuroki Y, Izumino H, Rinka H, Seo R, Takatori M, Kaneko T, Nakamura T, Irahara T, Saito N, Watanabe A; PiCCO Pulmonary Edema Study Group: The clinical usefulness of extravascular lung water and pulmonary vascular permeability index to diagnose and characterize pulmonary edema: a prospective multicenter study on the quantitative differential diagnostic definition for acute lung injury/acute respiratory distress syndrome. Crit Care 2012, 16:R232.

6. Jozwiak M, Silva S, Persichini R, Anguel N, Osman D, Richard C, Teboul JL, Monnet $X$ : Extravascular lung water is an independent prognostic factor in patients with acute respiratory distress syndrome. Crit Care Med 2013, 41:472-480.

7. Britos M, Smoot E, Liu KD, Thompson BT, Checkley W, Brower RG; National Institutes of Health Acute Respiratory Distress Syndrome Network Investigators: The value of positive end-expiratory pressure and $\mathrm{FiO}$ criteria in the definition of the acute respiratory distress syndrome. Crit Care Med 2011, 39:2025-2030.

doi:10.1186/cc1276

Cite this article as: Phillips CR: The Berlin definition: real change or the emperor's new clothes? Critical Care 2013, 17:174. 